\title{
Special Section on Mobile Multimedia Communications
}

\begin{abstract}
Along with the ongoing proliferation of $3 \mathrm{G}$ mobile terminals all over the world, how to provide advanced mobile multimedia services and applications is becoming the more important issue. Then, naturally, the researches and investigations supporting such services and applications are also becoming more important and highlighted in these days. For example, in April 2006, Japan started the terrestrial digital broadcasting service for mobile terminals, which is expected to enable the convergence between broadcasting and communication services, and also expected to provide a basis for highly sophisticated advanced multimedia services to mobile terminals. The same thing is happening in other countries based on DBV-H and DMB technologies.
\end{abstract}

Taking into account the aforementioned current trend, this special section is conducted by the study committee on Mobile Multimedia Communication, simply called MoMuC, succeeding the spirit of the ever published special issues or sections on the same subject; i.e. radio/wireless technologies are out of the scope, and authors are requested to clearly describe the mobile multimedia aspects.

For the call for paper to this special section, we received 50 papers and 6 letters. Among them, 14 papers and 2 letters were selected by the careful and fair review of the editorial committee. These papers cover the areas of scheduling algorithm, multimedia coding, multimedia application, mobile communication, multi-hop/ad-hoc/sensor networks, and network mobility.

The editorial committee hopes that these excellent papers contribute to the mobile technologies and the market progress. And as the editor-in-chief, I would like to express my sincere appreciation to all the authors for their contributions and all the members of the editorial committee for their hard works of review.

Special Section Editorial Committee Members

Guest Editors: Toshihiro Suzuki (NTT DoCoMo), Akira Yamaguchi (ATR)

Guest Associate Editors: Tomoyuki Ohya (NTT DoCoMo), Eiji Kamioka (National Institute of Informatics), Hideshi Murai (Ericsson), Ryoichi Shinkuma (Kyoto Univ.), Susumu Ishihara (Shizuoka Univ.), Katsunori Yamaoka (Tokyo Institute of Tech.), Susumu Yoshida (Kyoto Univ.), Miki Yamamoto (Kansai Univ.), Koji Ukena (Matsushita), Takashi Miyazaki (NEC), Masaki Minami (Shibaura Institute of Tech.), Minoru Okada (NAIST), Yoshimitsu Aoki (Shibaura Institute of Tech.)

Wataru Kameyama, Guest Editor-in-Chief

\begin{abstract}
Wataru Kameyama(Member) received the B.S., M.S., and Ph.D. degrees in electrical engineering from Waseda University in 1985, 1987, and 1990, respectively. He worked as an assistant professor at Waseda University from 1989 to 1992. After that, he joined ASCII Corporation in Japan, working on the multimedia standardization within the activities of ISO/IEC JTC1/SC29, and was responsible for multimedia system and terminal developments. During the work, he was transferred to France Telecom Research Institute, CCETT, Rennes, France, as a visiting researcher from 1994 to 1996, and contributed for the joint development of an interactive multimedia system as a prototype being compliant to the DAVIC specifications. In 1999, he was appointed as an associate professor at Global Information and Telecommunication Institute, Waseda University. And since 2002, we has worked as a professor at Graduate School of Global Information and Telecommunication Studies, Waseda University. His major research interests are multimedia information representation, interactive multimedia system and mobile multimedia services. He has been also actively working on international standardization activities, like MPEG, MHEG, DAVIC, and TV-Anytime Forum. He is an editor of ISO/IEC 13522-1 (MHEG-1) and ISO/IEC 13522-8 (MHEG-8), and worked as a convenor of ISO/IEC JTC1/SC29/WG12 from 2000 to 2001. And from August 2001 to August 2005, he served as a vice chairman of the TV-Anytime Forum. He is a member of IPSJ, ITE, IIEEJ, IEEE and ACM.
\end{abstract}

